\title{
Risk factors for hepatotoxicity from antituberculosis drugs: a case-control study
}

\author{
J N Pande, S P N Singh, G C Khilnani, S Khilnani, R K Tandon
}

\begin{abstract}
Background - Several risk factors for the development of hepatotoxicity during short course antituberculosis therapy have been suggested. A case-control study was undertaken to assess the role of age, sex, disease extent, nutritional status, past history of liver disease, infection with hepatitis viruses, acetylator status, and high alcohol intake as risk factors in the development of hepatotoxicity in patients with pulmonary tuberculosis receiving antituberculosis treatment.
\end{abstract}

Methods - The cases comprised 86 consecutive patients who were diagnosed as having hepatitis induced by antituberculosis drugs and who were negative for any of the hepatitis markers (HAVIgM, HBsAg, HBc-IgM, and anti-HCV). The control group comprised 406 consecutive patients attending the chest clinic who completed antituberculosis treatment without developing hepatitis. The variables analysed were age, sex, body mass index (BMI), history of high alcohol intake, radiological extent of the disease, acetylator status, and serum proteins.

Results - The cases were older and their serum albumin levels were lower than in the control group. High alcohol intake was more common among the cases, they had more extensive disease radiologically, and the proportion of slow acetylators was higher. No differences were observed between the two groups in the other risk factors analysed.

Conclusions - Of the various risk factors analysed, only advanced age, hypoalbuminaemia, high alcohol intake, slow acetylator phenotype, and extensive disease were risk factors for the development of hepatotoxicity. The risk of hepatitis in the presence of one or more of these risk factors may be increased.

(Thorax 1996;51:132-136)

Keywords: liver function tests, hepatitis markers, acetylator phenotype, pulmonary tuberculosis.

Tuberculosis continues to be a major health problem in both the developing and developed countries because of its resurgence in immunosuppressed patients. ${ }^{12}$ Short course chemotherapy containing rifampicin and isoniazid in combination has proved to be highly effective in the treatment of tuberculosis, but one of its adverse effects is hepatotoxicity. The mechanism of hepatotoxicity together with the risk factors that may predispose to its development are still not clearly understood. Wide variations have been found in the reported incidence of hepatotoxic reactions during short course chemotherapy. Studies from In $\operatorname{dia}^{3-6}$ have reported a much higher risk of hepatotoxicity than reports from the west ${ }^{7-9}$ using similar regimens. From an analysis of the pooled data from four prospective Indian studies $^{3-6}$ we calculated the risk of hepatitis to be $11.5 \%$ (95\% confidence interval (CI) 9.51 to 13.51 ), whereas a meta-analysis ${ }^{10}$ of 14 published studies from the west found the risk to be $4 \cdot 28 \%$ (95\% CI 3.38 to $5 \cdot 28)$. The reasons for this higher incidence of hepatotoxic reactions in India are not clear. It has been suggested that an apparently higher incidence of hepatitis in patients receiving antituberculosis therapy in India may be due to viral hepatitis which is particularly prevalent in developing countries. ${ }^{311}$ Furthermore, several risk factors for hepatotoxicity have been suggested such as advanced age, ${ }^{12}$ sex, ${ }^{13}$ poor nutritional status, ${ }^{14}$ liver disease, ${ }^{15}$ inappropriate use of drugs, chronic infections, hepatitis B virus (HBV) carrier status, ${ }^{16}$ acetylator status, ${ }^{1718}$ and high alcohol intake. ${ }^{13}$ We report the findings of a prospective case-control study undertaken to ascertain the role of these putative risk factors in the development of hepatitis in patients receiving short course chemotherapy for tuberculosis.

\section{Methods}

PATIENTS AND CONTROLS

Eighty six consecutive patients who presented to the outpatient department or were admitted in the All India Institute of Medical Sciences hospital with hepatitis due to short course antituberculous treatment during the period 1991-4 were prospectively included in the study. Twenty eight of the cases were being followed up and the other 58 were seen at the hospital for the first time after the development of hepatitis.

Four hundred and six consecutive patients diagnosed and treated for the full duration of chemotherapy with regular follow up in the chest clinic of the hospital during the same time period and without clinical or biochemical evidence of hepatitis formed the controls for this study.

DIAGNOSIS OF DRUG-INDUCED HEPATITIS The diagnostic criteria for drug-induced hepatitis were as follows: (1) clinical features of icteric hepatitis (anorexia, nausea, and jaun- 
dice); (2) serum aspartate aminotransferase (SGOT) and alanine aminotransferase (SGPT) levels of $>150 \mathrm{U} / 1$ on three consecutive occasions or $>250 \mathrm{U} / 1$ on one occasion; (3) serum total bilirubin of $>34.2 \mu \mathrm{mol} / \mathrm{l}$; and (4) absence of serological evidence of infection with hepatitis virus $\mathrm{A}, \mathrm{B}$, or $\mathrm{C}$. Viral hepatitis markers (HBsAg, IgM anti-HAV, IgM anti-HBc, and anti-HCV second generation antibodies) were analysed using ELISA immunoassay kits (Abbotts Laboratories).$^{19}$ All four of these criteria had to be fulfilled for the diagnosis of drug-induced hepatitis. Patients with associated chronic illnesses such as cirrhosis of the liver, chronic hepatitis, acute viral hepatitis, gastrointestinal, renal or cardiac disease, were excluded.

\section{DRUG REGIMENS}

The drug regimens used were as follows:

Regimen $1\left(2 \mathrm{RHE}_{7} / 7 \mathrm{RH}_{7}\right)$ : rifampicin plus isoniazid plus ethambutol daily for two months followed by rifampicin plus isoniazid daily for seven months.

Regimen $2\left(2 \mathrm{RHEZ}_{7} / 4 \mathrm{RH}_{7}\right)$ : rifampicin, isoniazid, ethambutol and pyrazinamide daily for two months followed by rifampicin and isoniazid daily for four months.

Regimen $3\left(2 \mathrm{SHRZ}_{7} / 4 \mathrm{RH}_{7}\right)$ : same as regimen 2 except for substitution of ethambutol by streptomycin.

Regimen $4\left(2 \mathrm{HRZ}_{7} / 4 \mathrm{RH}_{7}\right)$ : same as regimen 2 except for omission of ethambutol.

\section{DRUG DOSAGES}

The drug dosages were calculated in relation to the weight of the patients as follows:

(1) Streptomycin: $1.0 \mathrm{~g}$ parenterally for patients $<45$ years of age and $0.75 \mathrm{~g}$ for those $>45$ years.

(2) Rifampicin: body weight $<35 \mathrm{~kg}, 300 \mathrm{mg} /$ day; $\quad 36-50 \mathrm{~kg}, \quad 450 \mathrm{mg} /$ day; $>50 \mathrm{~kg}$, $600 \mathrm{mg}$ daily.

(3) Isoniazid: body weight $<35 \mathrm{~kg}, 200 \mathrm{mg} /$ day; $35 \mathrm{~kg}$ or more, $300 \mathrm{mg}$ daily.

(4) Ethambutol: $20 \mathrm{mg} / \mathrm{kg}$ body weight (rounded off to the nearest multiple of 200).

(5) Pyrazinamide: body weight $<50 \mathrm{~kg}, 1.0 \mathrm{~g}$ / day; $>50 \mathrm{~kg}, 1.5 \mathrm{~g} /$ day.

\section{STUDY DESIGN}

Full details of all antituberculosis treatment taken including dose, duration, and nature, presence of underlying liver disease, nutritional status, and alcohol intake were obtained in all patients. The disease was extensive if it involved the equivalent of more than one lung radiologically with multiple cavities. High alcohol intake was defined as $>6$ units ( $48 \mathrm{~g}$ ethanol) per day for more than one year. Liver function tests (serum bilirubin, serum transaminases, total protein, serum albumin and globulin, serum alkaline phosphatase) were performed on admission and every week after stopping treatment. Chemotherapy was continued with streptomycin and ethambutol until the SGOT/ SGPT levels returned to normal.
Table 1 Mean (SD) physical characteristics of the cases and controls

\begin{tabular}{lll}
\hline & $\begin{array}{l}\text { Cases } \\
(n=86)\end{array}$ & $\begin{array}{l}\text { Controls } \\
(n=406)\end{array}$ \\
\hline Age (years) & $39 \cdot 0(16 \cdot 2)$ & $31 \cdot 6(14 \cdot 5) *$ \\
M/F ratio & $1 \cdot 26$ & 1.90 \\
Height (m) & $1 \cdot 7(0 \cdot 1)$ & $1 \cdot 6(0 \cdot 1)$ \\
Weight (kg) & $48 \cdot 6(10 \cdot 8)$ & $49 \cdot 0(10 \cdot 4)$ \\
BMI (kg/m $\left.{ }^{2}\right)$ & $18 \cdot 1(4 \cdot 1)$ & $18 \cdot 6(4 \cdot 0)$ \\
ESR (Westergren, $\mathrm{mm} /$ & $47 \cdot 1(27 \cdot 7)$ & $42 \cdot 0(26 \cdot 9)$ \\
$\quad$ first hour) & 47.0 \\
\hline
\end{tabular}

$\mathrm{BMI}=$ body mass index; $\mathrm{ESR}=$ erythrocyte sedimentation rate. ${ }^{*} \mathrm{p}<0 \cdot 001$.

The acetylator status was estimated after recovery from hepatitis in 47 cases and before the start of treatment in 285 controls using the sulphadimidine test. ${ }^{20}$ In patients receiving antituberculous treatment, all drugs were stopped for 48 hours before the test.

\section{DATA ANALYSIS}

Cases and controls were compared using the Student's $t$ test for continuous variables (age, BMI, albumin) and the $\chi^{2}$ (Yates' corrected) for dichotomous variables (high alcohol intake, acetylator status, extensive disease). Cornfield $95 \%$ confidence limits were computed using the Epilnfo 6 program.

\section{Results}

The male/female ratio in the cases was 1.26 compared with 1.90 in the controls $(p=N S)$ and the age ranged from 15 to 70 years with a mean (SD) of $39.0(16 \cdot 2)$ in the cases and $31.6(14.5)$ in the controls $(p<0.001)$. The nutritional status as assessed by body mass index was similar in the two groups (cases $18 \cdot 1$ $(4 \cdot 1)$, controls $18 \cdot 6(4 \cdot 0)$ ) (table 1$)$. Baseline liver function tests were assessed before treatment in all the controls and in a variable number of cases, 28 of whom were being followed up at the chest clinic (table 2). In the remaining cases the levels were obtained after they were admitted to the hospital with jaundice (table 3). The cases had slightly lower serum albumin

Table 2 Mean (SD) results of pretreatment (baseline) liver function tests in cases and controls

\begin{tabular}{lcc}
\hline & Cases & $\begin{array}{l}\text { Controls } \\
(n=406)\end{array}$ \\
\hline $\begin{array}{l}\text { Serum bilirubin } \\
\quad(\mu \mathrm{mol} / \mathrm{l})\end{array}$ & $11 \cdot 9(5 \cdot 1)(\mathrm{n}=45)$ & $11 \cdot 8(4 \cdot 79)$ \\
SGOT $(\mathrm{U} / 1)$ & $44 \cdot 7(23 \cdot 9)(\mathrm{n}=45)$ & $39 \cdot 1(25 \cdot 3)$ \\
SGPT (U/1) & $35 \cdot 8(21 \cdot 8)(\mathrm{n}=45)$ & $35 \cdot 3(35 \cdot 9)$ \\
Serum alkaline & & \\
$\quad$ phosphatase (U/1) & $208(156)(\mathrm{n}=45)$ & $183 \cdot 9(139 \cdot 9)$ \\
Serum albumin $(\mathrm{g} / \mathrm{l})$ & $37 \cdot 9(9 \cdot 7)(\mathrm{n}=35)$ & $42 \cdot 0(7 \cdot 0)$ \\
Serum globulin $(\mathrm{g} / \mathrm{l})$ & $37 \cdot 2(8 \cdot 3)(\mathrm{n}=35)$ & $36 \cdot 0(8 \cdot 0)$ \\
\hline
\end{tabular}

Table 3 Mean (SD) results of liver function tests in cases (with hepatitis) during peak hyperbilirubinaemia

\begin{tabular}{lc}
\hline & $\begin{array}{l}\text { Cases } \\
(n=86)\end{array}$ \\
\hline Serum bilirubin $(\mu \mathrm{mol} / \mathrm{l})$ & $59 \cdot 85(76 \cdot 9)$ \\
SGOT $(\mathrm{U} / \mathrm{l})$ & $411 \cdot 2(632 \cdot 2)$ \\
SGPT $(\mathrm{U} / 1)$ & $427 \cdot 9(770 \cdot 9)$ \\
Serum alkaline phosphatase $(\mathrm{U} / \mathrm{l})$ & $321 \cdot 98(263 \cdot 3)$ \\
Serum albumin $(\mathrm{g} / \mathrm{l})$ & $34 \cdot 0(9 \cdot 0)$ \\
Serum globulin $(\mathrm{g} / \mathrm{l})$ & $39 \cdot 0(11 \cdot 0)$ \\
\hline
\end{tabular}


Table 4 Drug regimens used

\begin{tabular}{lllcl}
\hline No & Regimen* & $\begin{array}{l}\text { Duration } \\
\text { (months) }\end{array}$ & Cases & Controls \\
\hline 1 & 2RHE $_{7} /$ RRH $_{7}$ & 9 & 32 & 304 \\
2 & 2RHEZ $_{7} / 4 \mathrm{RH}_{7}$ & 6 & 39 & 102 \\
3 & $2 \mathrm{SHRZ}_{7} / 4 \mathrm{RH}_{7}$ & 6 & 9 & - \\
4 & $2 \mathrm{HRZ}_{7} / 4 \mathrm{RH}_{7}$ & 6 & 6 & - \\
\hline
\end{tabular}

${ }^{*}$ For details of regimens see text.

levels before the start of treatment but this was not significant statistically.

The drug regimens used are shown in table 4. Fifty four of the 86 cases and 102 of the 406 controls had received chemotherapy regimens containing pyrazinamide in addition to rifampicin and isoniazid. This difference was statistically significant (Yates' corrected $\chi^{2}=$ $\left.44.76 ; \mathrm{p}=0.1 \times 10^{-7}\right)$. Furthermore, the control patients were more likely to have received pyrazinamide-containing regimens if they had extensive disease (odds ratio $(O R)=3 \cdot 14 ; 95 \%$ CI 0.96 to $10 \cdot 21$ ), and this trend was not seen amongst the cases.

The latency period between the start of treatment and development of hepatitis in the cases was 49 days, and in most cases, hepatitis was evident within three months of the start of antituberculous treatment. However, 15 of the cases developed hepatitis after a mean period of five months from the start of treatment and two of these 15 cases developed hepatitis after 7.5 months of treatment. Liver function status before starting antituberculosis treatment was known in only 45 of the cases including 28 who were being followed up at the hospital (table 2). The baseline values of SGOT/SGPT were similar in the two groups. All cases showed clinical signs of jaundice with significantly raised transaminases. The transaminases were also significantly increased during chemotherapy in the controls but did not exceed more than four times the upper limit of the normal range (SGOT/SGPT up to $37.5 \mathrm{U} / 1$, serum alkaline phosphatase up to $280 \mathrm{U} / 1$, serum bilirubin up to $17 \cdot 10 \mu \mathrm{mol} / \mathrm{l})$. In the control group $41 \cdot 1 \%$ had a peak elevation of SGOT in the

Table 5 Dichotomous variables in cases and controls

\begin{tabular}{lllll}
\hline & $\begin{array}{l}\text { Cases } \\
(n=86)\end{array}$ & $\begin{array}{l}\text { Controls } \\
(n=406)\end{array}$ & $\chi^{2} \dagger$ & $\begin{array}{l}\text { Odds ratio } \\
(95 \% C I)\end{array}$ \\
\hline High alcohol intake & $19.8 \%$ & $4.9 \%$ & 20.4 & $\begin{array}{l}4 \cdot 76 \\
(2.25 \text { to } 10.05)^{*}\end{array}$ \\
Extensive disease & $14.0 \%$ & $3.5 \%$ & 13.6 & $\begin{array}{l}4.5 \\
(1.88 \text { to } 10.93)^{*}\end{array}$ \\
Slow acetylator & $82.9 \%$ & $64.2 \%$ & 5.60 & $\begin{array}{l}2.72 \\
(1.16 \text { to } 6.57)^{* *}\end{array}$ \\
Jaundice in past & $11.6 \%$ & $10.8 \%$ & 0.001 & $\begin{array}{l}1.08 \\
(0.49\end{array}$ \\
Pyrazinamide in regimen 2.35$)$ \\
\hline
\end{tabular}

${ }^{*} \mathrm{p}<0.001 ;{ }^{* *} \mathrm{p}<0.01 ;{ }^{* * *} \mathrm{p}<0.1 \times 10^{-7}$

† Yates' corrected $\chi^{2}$.

Table 6 Effect of disease extent on risk of hepatitis: stratified analysis according to drug regimens

\begin{tabular}{lcclc}
\hline & Cases & Controls & Odds ratio & $95 \%$ CI \\
\hline $\begin{array}{l}\text { No pyrazinamide } \\
\quad \text { Extensive disease }\end{array}$ & 4 & 7 & 5.85 & 1.34 to 24.16 \\
$\quad$ Limited disease & 29 & 297 & & \\
$\begin{array}{l}\text { Pyrazinamide } \\
\quad \text { Extensive disease }\end{array}$ & 8 & 7 & 2.41 & 0.74 to 7.98 \\
Limited disease & 45 & 95 & & \\
\hline
\end{tabular}

range $38-80 \mathrm{U} / 1,9 \cdot 6 \%$ in the range $81-120 \mathrm{U} /$ 1 , and $3 \cdot 7 \%$ in the range $121-150 \mathrm{U} / 1$. Ten cases $(11.6 \%)$ and 44 controls $(10.8 \%)$ had a past history of hepatitis, but this difference was not statistically significant.

The proportion of patients with a high alcohol intake was significantly higher amongst the cases than the controls $(19 \cdot 8 \%$ versus $4.9 \%$; $\mathrm{OR}=4.76,95 \%$ CI 2.25 to $10.05 ; \mathrm{p}<0.001$ ) (table 5).

The disease extent was also a significant risk factor for the development of hepatitis, with $14 \%$ of the cases having extensive disease but only $3.5 \%$ of the controls (OR $=4.54,95 \% \mathrm{CI}$ 1.88 to $10.93, \mathrm{p}<0.001)$. Four of the cases $(4 \cdot 6 \%)$ and six of the controls $(1 \cdot 5 \%)$ had miliary shadows on their radiographs. The presence of miliary tuberculosis was not associated with any increased risk for the development of hepatitis.

The acetylator status was assessed in 47 cases and 285 controls (table 5), and the ratio of slow to fast acetylators in the two groups was 5.0 and 2.0 , respectively. This difference was statistically significant (OR $=2 \cdot 72 ; 95 \%$ CI $1 \cdot 16$ to $6.57, \mathrm{p}<0.01)$. There were more slow acetylators in both groups.

Of the 86 cases who developed antituberculosis treatment-induced hepatitis, five $(6 \%)$ died of fulminant hepatic failure. Two of these five cases were being treated at our hospital and neither had abnormal liver function tests before starting treatment. There were no deaths in the control group.

\section{Discussion}

The development of drug-induced hepatitis during chemotherapy for tuberculosis is of great concern as it necessitates cessation or modification of treatment. Steele $e t$ al ${ }^{10}$ reported in a meta-analysis that isoniazid and rifampicin given together produce hepatotoxicity more frequently than isoniazid alone. Wide variations in the incidence of hepatotoxic reactions during isoniazid and rifampicin therapy have been reported. The relatively higher incidence of hepatotoxicity in the developing countries has been attributed to various factors such as older age, higher alcohol intake, malnutrition, intestinal parasitism, past history of jaundice, chronic liver disease, indiscriminate use of drugs, and viral hepatitis. ${ }^{21}$ There is no consensus as to which one of these factors, whether alone or in combination, is involved in the development of drug-induced hepatitis and whether any could be used as markers to identify patients at higher risk. It would be advantageous to identify this high risk group as toxic hepatitis complicates the management of tuberculosis. Once identified these patients can be monitored carefully for hepatotoxicity as antituberculosis treatment-induced hepatitis causes a mortality of $6-12 \%$ if the drugs are continued after the onset of symptoms. ${ }^{22}$

Our finding that hepatitis induced by antituberculosis treatment is more frequent in older patients $(p<0.001)$ is in agreement with earlier studies $^{12}$ where the risk of antituberculosis treatment-induced hepatitis increases with age 
and the highest incidence occurs in individuals above 50 years. Moreover, women appeared to develop hepatitis more commonly (44\% compared with $34 \%$ in the non-hepatitis group), although this difference was not significant. Others ${ }^{1316}$ have also reported a female preponderance amongst those developing hepatitis.

Poor nutritional status has been considered to be one of the factors contributing to the high incidence of hepatitis induced by short course chemotherapy for tuberculosis in the developing countries. Mehta $e t a l^{6}$ have reported a threefold greater incidence of hepatotoxicity in malnourished children with a regimen containing rifampicin and isoniazid. In our study the BMI of the cases and controls was similar. However, the serum albumin was significantly lower in the cases during hepatitis than in the controls $(p<0 \cdot 001)$. There was no significant difference in the serum albumin among the patients with extensive or limited disease. It appears that undernutrition as identified by hypoalbuminaemia may in itself be a risk factor for drug-induced liver injury. The possibility that hypoalbuminaemia was caused partly by the development of hepatitis itself cannot be ruled out. However, the duration of the illness at the time of inclusion in the study was 1-10 days, and it is unlikely that this brief illness would have resulted in hypoalbuminaemia. The pretreatment serum albumin levels in the 35 cases in whom the results were available were lower than in the controls, but this difference was not significant.

In agreement with earlier reported data, ${ }^{13}$ high alcohol intake was a significant risk factor for the development of drug-induced hepatitis. High alcohol intake was recorded in $19.8 \%$ of the cases compared with $4.9 \%$ of the controls $(p<0.001)$, indicating that consumers of high alcohol are more prone to develop hepatotoxicity.

The disease extent was also a significant risk factor for the development of hepatitis, with 12 of the 86 cases $(14.0 \%)$ having extensive disease but only 14 of the 406 controls (3.5\%).

The drug regimens used for the cases and controls were different, with pyrazinamide being used more often in the treatment of the cases than in the controls. At the beginning of the study three drug regimens using RHE were popular for patients with limited disease at our hospital, with RHEZ being used for patients with more extensive disease. With increasing emergence of initial resistance to one or more drugs in India, it is now considered advisable to use RHEZ for all patients unless contraindicated. ${ }^{23}$ Furthermore, patients (cases and controls) with extensive disease were also more likely to have received regimens containing pyrazinamide $(\mathrm{OR}=3 \cdot 18 ; 95 \% \mathrm{CI} 1 \cdot 34$ to $7 \cdot 61$ ). Several investigators have shown that the addition of pyrazinamide to the regimen does not increase its hepatotoxicity. ${ }^{24}$ However, stratification of cases and controls on the basis of the inclusion of pyrazinamide in the regimen showed that extensive disease was significantly more frequent among the cases $(O R=5 \cdot 85$; $95 \%$ CI $1 \cdot 34$ to $24 \cdot 16$ ) than among the controls in the subgroup that received no pyrazinamide. A similar, but not statistically significant association, was also seen in the subgroup that received regimens containing pyrazinamide ( $\mathrm{OR}=2 \cdot 41 ; 95 \%$ CI 0.74 to 7.98 ) (table 6 ).

With regard to acetylator status and the risk of developing hepatitis, the reported data show no consensus. Both fast and slow acetylators have been reported to be more prone to developing hepatotoxicity on short course chemotherapy. ${ }^{31718} \mathrm{We}$ observed the ratio of slow to fast acetylators in cases and controls to be $5 \cdot 0$ and $2 \cdot 0$, a difference which was statistically significant, and suggests that the risk of developing hepatitis is greater among slow acetylators. Ours was a case-control study in patients admitted to hospital with clinical jaundice, whereas the observations made by Gurumurthy $e t a l^{17}$ and Parthasarthy et $a l^{\beta}$ were based on prospective cohort studies from a large study on south Indian patients with tuberculosis. The severity of jaundice in these studies is different, with our patients being more ill and requiring admission to hospital for their hepatitis. It is therefore possible that the slow acetylator phenotype may predispose to more severe forms of hepatotoxic reactions with antituberculous drugs. In many cases the acetylator status could not be determined as they were too ill at the time of registration.

This study excludes all patients who developed viral hepatitis during antituberculosis treatment, although the possibility that a few of them had viral hepatitis that was not detected by the serological tests used cannot be excluded. Serological markers were evaluated only for hepatitis A, B, and C virus. Kumar et $a l^{11}$ and Turktas $e t a l^{25}$ concluded that the reported high incidence of drug-induced hepatitis in developing countries was, to a significant extent, attributable to these viral infections.

Being a case-control study, we are in no position to comment on the risk of the development of hepatitis in patients given antituberculous drug regimens containing rifampicin and isoniazid, but the development of drug-induced hepatitis appears to be influenced by the risk factors discussed here. Our findings suggest that older patients with low serum albumin levels, greater disease extent, slow acetylator phenotype, and with a higher alcohol consumption have a higher risk for the development of drug-induced hepatotoxicity. The risk of developing hepatitis in the presence of one or more of these factors may be appreciably higher. Some of the risk factors namely, high alcohol intake, extensive disease possibly with dissemination to the liver, and hypoalbuminaemia - appear to be interrelated and may ultimately influence the hepatic metabolism of drugs such as isoniazid and rifampicin, thereby enhancing their hepatotoxicity.

Prospective studies on large numbers of patients are necessary to substantiate the findings of this case-control study.

This study was supported by grants from the Medical Research Council, UK, and the Indian Council of Medical Research, 
New Delhi. The authors wish to thank Mrs Raj Rani for technical assistance.

1 Spence D. Tuberculosis and poverty. BMF 1993;307:759 60.

2 Davidson PT, Quoc Le H. Drug treatment of tuberculosis. Drugs 1992;43:651-73.

3 Parthasarthy R, Raghupati Sarma G, Janardhanam B, Ramachandran P, Santha T, et al. Hepatic toxicity in south Indian patients during treatment of tuberculosis with short-course regimens containing isoniazid, rifampicin and pyrazinamide. Tubercle 1986;67:99-108.

4 Purohit SD, Gupta PR, Sharma TN, Gupta DN, Chawl MP. Rifampicin and hepatic toxicity. Indian $\mathcal{F}$ Tuberc 1983 30:107-9.

5 Taneja DP, Kaur D. Study on hepatotoxicity and other side effects of antituberculosis drugs. $\mathcal{F}$ Indian Med Assoc 1990 88:278-80.

6 Mehta S. Malnutrition and drugs: clinical implications. Dev Pharmacol Ther 1990;15:159-65.

7 Snider DE, Long MW, Cross FS, Farer LS. Six months isoniazid and rifampicin therapy for pulmonary tuberculosis. Report of a United States Public Health Service culosis. Report of a United States Public Health Ser.

8 Dutt AK, Moers D, Stead WW. Short course chemotherap for tuberculosis with mainly twice-weekly isoniazid and rifampicin. Community physicians' seven year experience with mainly outpatients. Am F Med 1984;77:233-42.

9 British Thoracic and Tuberculosis Association. Short course chemotherapy in pulmonary tuberculosis. Lancet 1975; 119-24.

10 Steele MA, Burk RF, Desprez RM. Hepatitis with isoniazid and rifampicin - a meta analysis. Chest 1971;99:465-71.

11 Kumar A, Misra PK, Mehrotra R, Govil YC, Rana GS Hepatotoxicity of rifampicin and isoniazid: is it all drug induced hepatitis? Am Rev Respir Dis 1991;143:1350-2.

12 induced hepatitis? Am Rev Respir Dis 1991;143:1350-2. on Tuberculosis. Preventive treatment of tuberculosis. on Tuberculosis. Preventive treat $1985 ; 87$ (Suppl 2):128-32.
Chest
13 Gronhagen RC, Hellstrom PE, Froseth B. Predisposing factors in hepatitis induced by isoniazid-rifampicin treat-

14 Rugmini PS, Mehta S. Hepatotoxicity of isoniazid and rifampicin in children. Indian 7 Pediatr 1984;21:119-24.

15 Riska N. Hepatitis cases in isoniazid treated groups and in a control group. Bull Int Union Tuberc 1976.51:203-6.

a control group. Bull Int Union Tuberc 1976;51:203-6. hepatitis in hepatitis B carriers. Gastroenterology 1990;98: 502-4.

17 Gurumurthy $P$, Krisnamurthy MS, Nazareth O, Parthasarthy R, Raghupati Sarma P, Somasundaran PR, et thasarthy $\mathrm{R}$, Raghupati Sarma $\mathrm{P}$, Somasundaran $\mathrm{PR}$, et
al. Lack of relationship between hepatic toxicity and acet al. Lack of relationship between hepatic toxicity and acet-
ylator phenotypes in 3000 south Indian patients during treatment with isoniazid for tuberculosis. Am Rev Respi Dis 1984;129:58-61.

18 Mitchell JR, Thorgiersson UP, Black M. Increased incidence of isoniazid hepatitis in rapid acetylators: possible relations to hydrazine metabolites. Clin Pharmacol Ther 1975;18 70-9.

19 Engvali E, Perlmann P. Enzyme linked immunosorbent assay (ELISA). Quantitative assay of immunoglobulin G. Immunochemistry 1971;8:871-4

20 Rao KVN, Mitchison DA, Nair NGK. Sulphadimidine acetylation test for classification of patients as slow or rapid inactivators of isoniazid. $B M \mathcal{F} 1970 ; 3: 495-7$.

21 Gangadharan PRJ. Isoniazid, rifampicin and hepatotoxicity. Am Rev Respir Dis 1986;133:963-5.

22 Dash LA, Comstock GW, Flynn PG. Isoniazid preventive therapy: retrospect and prospect. Am Rev Respir Dis 1980; 121:1039-44.

23 Bass JB, Farer LS, Hopewell PC, O'Brien R, Jacobs RF Ruben $\mathrm{F}$, et al. Treatment of tuberculosis and tuberculosis infection in adults and children. Am $\mathcal{J}$ Respir Crit Care Med 1994;149:1359-74.

24 Girling DJ. The hepatic toxicity of anti-tuberculosis regimens containing isoniazid, rifampicin and pyrazinamide. gimens containing isonia

25 Turktas H, Unsal M, Tulek N, Oruc O. Hepatotoxicity of antituberculosis therapy (rifampicin, isoniazid and pyrazinamide) or viral hepatitis. Tubercle Lung Dis 1994 75:58-60. 